\title{
Design of Practice Teaching Management Platform for Undergraduate Colleges Based on Distributed Theory
}

\author{
Han Guang \\ The Academic Affairs Office, Jilin AgriculturalUniversity, Changchun, 130118, China
}

Keywords: Open experiment, Teaching management system, B/S system structure, Reservation management, Database.

\begin{abstract}
The open experimental teaching management system is an indispensable part of the education unit, its content will bring great convenience to the school administrators, teachers and students. It can realize the computer management of the whole process of experiment teaching, reduce the burden of the experimental teaching management personnel, and improve the work efficiency and service level. With modern educational technology and means to stimulate students' interest and desire for knowledge, to inspire students' autonomy and enthusiasm, so that students have great interest in the experiment. This paper expounds the development and design idea of Web based open experiment teaching management system management subsystem, and the method and process of realizing the information exchange between the front desk and the backstage by using ASP technology. The system uses B/S architecture, which can meet the requirements of centralized educational administration users, large amount of data processing, and meet the students' maximum use of the system. Through the demonstration of computer hardware and software solutions, the investigation and analysis of the application field, referring to various materials and database programming practice, successfully achieved the basic design requirements. We design the database system to achieve laboratory management, reservation management, experimental project management, user management, bulletin management and other functions.
\end{abstract}

\section{Introduction}

For a long time, the traditional experimental teaching management has brought a lot of inconvenience to students, teachers and administrators. Students can not choose experiment course, project, proper time, teacher and so on. Students can only accept the arrangement passively. Moreover, the experiment teaching management work is complex, tedious, fixed mode, frequent information exchange, wasting a lot of people's time and energy. With the gradual progress of university management reform and the further standardization and complexity of laboratory construction, the management of experimental teaching in Colleges and universities has become more onerous and complex. This is an urgent need for computer aided management to simplify our work. At present, the university network has been very popular, the use of computer network to carry out experimental teaching management has become inevitable, especially the laboratory open course selection to the traditional laboratory management put forward new challenges. The experimental teaching management system can realize the computer management of the whole process of experimental teaching, reduce the workload of the experimental teaching management personnel, and improve the work efficiency and service level. Experimental teaching management system can also provide raw data and basic data for experimental teaching evaluation, and become an important basis for the evaluation of experimental teaching [1].

In the use of teaching methods, through a variety of modern educational technology and means to stimulate students' interest and desire for knowledge, autonomy and enthusiasm of the students, so that students have great interest in this experiment, but not tired. In the new century, the opening 
of experimental teaching is an important subject in the experimental teaching reform in Colleges and universities. Opening up is conducive to make full use of experimental teaching resources, stimulate students' enthusiasm for independent learning, and cultivate innovative talents to meet the requirements of the new era.

\section{System Design}

\section{1 design principles}

The Web experiment teaching management system should have such functions in the campus based on any networked computer, students can carry out experiments, results and some other related information query and experiment booking, enrollment operation. The teachers can easily input student experimental results, and to statistical information query course, laboratory, etc., a reasonable performance evaluation methods, can give full play to the role of ground award and punish lazy; security corresponding, to avoid the loss or destruction of the reservation information data, and the experimental results are not tampered with; to establish an effective channel of communication between teachers and students.

To achieve these goals, the system design must follow the following principles [2]:

1. faster response speed and higher working rate;

2. make full use of existing resources, including LAN, data and so on, and minimize repeated investment;

3. adaptable, expandable, easy to maintain and easy to operate;

4. effectively handle concurrent operations on data access.

\section{2 system advantages}

1. advanced management thought

The system integrates the experience of educational administration and educational administration reform for many years. Centralized management of educational data, to maximize the realization of data sharing, to avoid the emergence of management loopholes, and provide detailed data for school management decision support.

2. comprehensive experimental teaching management system

It involves all aspects of experimental teaching management, and provides services for all levels of users, such as educational administration departments, teachers and students.

3. advanced technology

The system runs on Internet, and uses B/S architecture to meet the requirements of centralized educational administration users, large amount of data processing, and to meet the students' maximum use of the system.

4. modular software architecture

Each subsystem can run independently, and can also run jointly to realize data sharing.

\section{3 design thought}

The experimental teaching management system based on Web, in essence, is to realize the remote Web access of the reservation information database on the campus network. There are many ways to access database on Web platform. It can be through the CGI (Common Gateway Interface, common gateway interface), JDBC (Java Database Connectivity connection technology, Java and database), SSI (Server Side Include server plugin), ISAPI (Internet Server Application Program Interface server application programming interface), can also be used to provide special development tools, Oracle Sybase database system, establish a connection between dynamic HTML pages and database, so that the browser can realize the database using SQL queries, and even increase, delete, modify the database information [4]. In the physical implementation, the system uses B/S (Browser/Server, browser / server) structure system. 
The front end Web browser sends the command request or accepts the data to the database through the Web server, between the Web server and the database uses ODBC to carry on the communication. This architecture is convenient for centralized management. The application, database and related components are all concentrated on the server, and the client only needs a Web browser. Moreover, the system update, maintenance and data management are implemented on the server, which is conducive to system management.

\section{Design of Practice Teaching Management Platform}

Using web maps, you can quickly create, prototype, update, and reorganize web pages. Changing the location of a web page or file name, Dreamweaver automatically updates all links. The use of support text, HTML code, HTML attribute tags and general syntax search and replace function makes complex website updates become fast and simple.

Dreamweaver is the only design tool that provides synchronization between Roundtrip HTML and visual editing and source code editing. The frames (frames) and tables are so fast that you can't imagine them. Advanced table editing feature allows you to simply choose the single row, column or not, continuous selection. You can even sort or format table groups, Dreamweaver support precise positioning, using easily converted to the form of the layer to drag placement layout layout.

\section{Dreamweaver}

The successful integration of dynamic visual editing and publishing of electronic commerce, providing a strong support to the Third-party manufacturers, including ASP, Apache, BroadVision, Cold, Fusion, iCAT, Tango and self-developed application software. When you're using Dreamweaver to design dynamic web pages, the available features allow you to preview the web without having to browse through the browser.

The web page designed by Dreamweaver can be displayed in any popular browser on any platform. Using different browser checking capabilities, Dreamweaver can tell you how effective you're performing on different browsers. When a new browser is listed, a detailed report of the results can be obtained as long as it is downloaded from the Dreamweaver web site.

B/S (Browser/Server) structure, namely browser and server structure. It is a change or an improved structure of $\mathrm{C} / \mathrm{S}$ with the rise of Internet technology. In this structure, the user interface is implemented by WWW browser, little business logic in front (Browser), but the main business logic on the server (Server), forming a so-called three layer 3-tier structure. This greatly simplifies the client computer load, reduces the cost and workload of system maintenance and upgrades, and reduces the total cost of the user (TCO).

(1) maintenance and upgrade are simple

At present, the improvement and upgrade of software system are more and more frequent, and the products of $\mathrm{B} / \mathrm{S}$ architecture are obviously more convenient. On a slightly larger unit, system managers if needed in the hundreds or even thousands of computer running back and forth between efficiency and workload is, as can be imagined, but only need B/S software management server on the line, all the client browser only, this need not do any maintenance. Regardless of size, number of branch will not increase any maintenance workload, all the operation only for the server; if it is remote, only need to connect server network can realize the maintenance, upgrading and remote sharing.

(2) reduce costs, choose more

As you all know, windows has almost dominated the desktop computer, and browsers have become the standard configuration, but windows is not in absolute dominance on the server operating system. Now the trend is that the use of $\mathrm{B} / \mathrm{S}$ architecture application management software, only installed on the Linux server can be, and high security. So the server operating system is the choice of many, no matter choose the kind of operating system can make most people use windows as a desktop operating system is not affected by the development of computer, which makes the most popular free Linux operating system, Linux operating system is free except outside, even the database is free of charge, this choice is very popular. 


\section{System Analysis}

In the traditional experimental teaching, the experimental teacher is the main body of imparting knowledge and skills, while the students only need to operate according to the prescribed steps. Students learn very little, the ability to practice is poor. Moreover, students can only passively accept the arrangement of experimental courses, projects, appropriate time, teachers and so on. Administrators and teachers should be responsible for teaching, teaching and research, assessment and many other tasks. The work is complex, tedious, fixed mode, frequent information exchange, wasting a lot of time and effort. Today, network development is very common, and many jobs can be done accurately and efficiently through specific system functions.

Administrators are mainly to deal with data, you can add, delete and modify teachers, students, courses, projects, laboratories and other information. The curriculum and project submitted by teachers are audited, and the corresponding feedback information is given. Arrange and update spare lab information in time so that teachers can inquire and choose. Users can use the statistical query function of the system to conveniently and quickly count, query, make appointments for student lists, projects, experimental class hours and other information. Some announcements, feedback and other information can be obtained from the information management module in time. The system is easy to use and easy to operate.

\section{5 . Summary}

From this design, I learned the SQL Server 2000 database management function; visual programming features of Dreamweaver MX, it sets the "production and management of Web sites in a WYSIWYG web page editing; powerful ASP development of a dynamic Web page technology and Visio tools; powerful drawing function. From the results of the current system operation, the analysis and design of the system management subsystem and the implementation of the system, meet the basic needs of the current experimental teaching management. However, with the development of computer technology and the change of the management requirements of experimental courses, the experimental teaching management system will continue to improve, and we will face new challenges.

\section{References}

[1]Pahlavan K, Krishnamurthy $\mathrm{P}$ and Geng $\mathrm{Y}$, Localization challenges for the emergence of the smart workd. IEEE Access, 2015, 3(1), pp. 3058-3067

[2]Lv, Z., Tek, A., Da Silva, F., Empereur-Mot, C., Chavent, M., \&Baaden, M. (2013). Game on, science-how video game technology may help biologists tackle visualization challenges. PloS one, 8(3), e57990.

[3]Lv, Z., Halawani, A., Feng, S., Li, H., \&Réhman, S. U. (2014). Multimodal hand and foot gesture interaction for handheld devices. ACM Transactions on Multimedia Computing, Communications, and Applications (TOMM), 11(1s), 10.

[4]Weisen Pan, Shizhan Chen, ZhiyongFeng. Automatic Clustering of Social Tag using Community Detection. Applied Mathematics \& Information Sciences, 2013, 7(2): 675-681. 